RESEARCH ARTICLE

\title{
Effect of Various Light Conditions on Vertebral Column Shape from Pre to Post Spawning Phases in Clarias batrachus: an Indian Cat fish
}

\section{Shweta Agniwanshi}

Department of Zoology, Dr Radha Bai Govt Naveen Girls College, Raipur, 492001, Chhattisgarh, India

Study Area: Raipur, Chhattisgarh, India Coordinates: $21.25^{\circ} \mathrm{N} ; 81.63^{\circ} \mathrm{E}$

Key words: Lordotic vertebrae, Scoliosis, Light and dark therapy

Abbreviation used: LL- constant light conditions; DDconstant dark conditions

\section{Abstract}

Present study was aimed to examine the effect of constant light (LL) and constant dark (DD) on vertebral column in Indian fresh water cat fish, Clarias batrachus. Experiments were carried out during different phases of the annual reproductive cycle of the fish i.e., pre spawning, spawning and post spawning phases for three consecutive years. During each experimental protocol, four animals from each group were dissected out at every 15 days to observe changes occurring in the vertebral column. It was found that the animals maintained under DD exhibit bending of vertebral column at abdominal region (scoliosis) during pre spawning and spawning phases, irrespective of year of study. We also found, the bending of skeleton increases with the days of exposure under DD. However, these changes were not seen in other groups. Thus, it could be concluded that the exposure under DD may be a stress condition for the fish, C. batrachus specially during its high energy demanding phases like pre spawning and spawning phases.

al., 1979; Backiel et. al., 1984; Weis \& Weis., 1989; Wiegand et al., 1989), nutritional deficiency in the feeds (Rucker et al.,1970; Lim \& Lowell ;1978; Akiyama et al., 1985; Dabrowski et al.,1988; Frischknecht et al., 1994; Quigley; 1995) a genetic mutation (Mair,1992), or a combination of these factor (Al-Harbi, 20o1). Further, seasonal effect of continuous light on the growth of different region of the vertebral column in Atlantic salmon was also reported by Fjelldal et al., (2005) and Wargelius et al.,(2008). Light intensity has also been reported to cause aberrations in the development of the vertebral column (Carls \& Rice,1990). Lordosis in fish was reported as an abnormal ventral curvature of the vertebral column, accompanied by abnormal calcification of the afflicted vertebrae and a bulking failure of the vertebral column (Kranenbarg et al., 2005) and one of the most severe deformities develop in reared fish (Fjelldal et al., 2006). Further, skeletal anomalies were used as an indicator of pollution stress in fish (Bengtsson et al., 1985; Karen et al., 2001; Klumpp et al., 2002; Boglione et al., 1989). Reports on the effect of constant light and dark on the growth of vertebral column in fish are scarce. Thus the present study was aimed to examine the effect of continuous light (LL) and continuous dark (DD) on the growth of vertebral column in a freshwater catfish, Clarias batrachus. 


\section{Methodology:}

Live Clarias batrachus of mixed sex (body weight $70 \pm \mathrm{gm}$ ) were procured from the local fish market during different phases (pre-spawning, spawning, and post-spawning) of its annual reproductive cycle. During each phase, prior to starting the experiment animals were kept in stock aquaria for proper acclimation. Following acclimation, animals were divided into three groups ( $\mathrm{n}=18$, in each group) and maintained under different photoperiods i.e., natural day length (control), continuous light (LL) and continuous dark (DD) for 6o days. Experiments were carried out for three consecutive years. During each experimental protocol, four animals from each group were dissected out successively in every 15 days and visual analysis of the structure of vertebral column was made during experiment water inside the aquaria was renewed every alternate day and animals were fed ad labium.

\section{Results :}

(Results were summerized in Figure-1 to 3 )

Natural day length (NDL; control): visual observation of the structure of vertebral column has revealed normal standard change in growth of vertebral column in the group kept under NDL and was treated as control during different phases of annual reproductive cycle (Fig.-1a).

Constant light (LL): like control visual analysis of the vertebral column showed no deformities in its structure during different studied phases of annual reproductive cycle.

Constant dark (DD): in contrast, in most of the fish maintained under constant dark, curvature in vertebral column at trunk/abdominal region (lordosis) were observed during pre-spawning (Fig.-2 a,b(i \& ii) and spawning phases (Fig.-3a,b,c), irrespective of years of the study.

Further, it has also been observed that the angle of curvature increases with the days of exposure (Fig.-2 a,b(i \& ii) \& 3a,b,c). In addition, fusion in some trunk vertebrae with decreased intervertebral and inter-rib space were noticed (Fig.-3b,c).

\section{Discussion:}

Skeleton deformities ir-reversely affect the production cost, biological performances and marketing image of the fish (Afonso et al.,200o).

A wide range of physico-chemical and biological factors like temperature (Sfakianskis et al., 2004), light (Biswas et al., 2006), stress (Valenzuela et al., 2007), parasite (Lom et al.,1991) and pollution (Bengtsson et al., 1985; Jawad et al.,2017) had already reported to cause spinal deformities in various fish species.

Similarly, present results revealed the occurrence of lordosis and fusion of some vertebrae in the group of Clarias batrachus maintained under constant dark. However, no

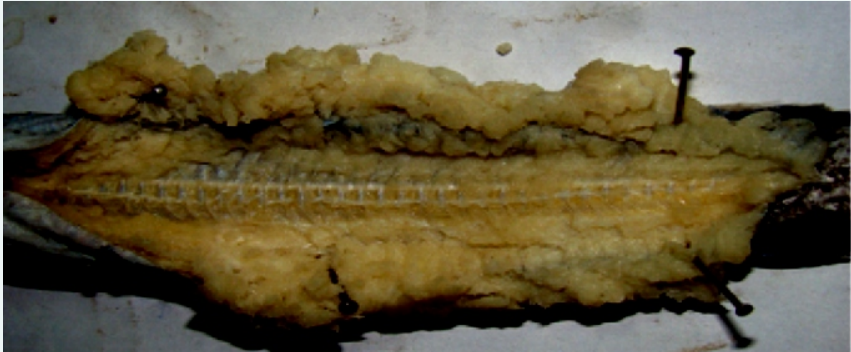

Figure 1: Vertebral column (Lordotic vertebrae) of C. batrachus almost straight in control group
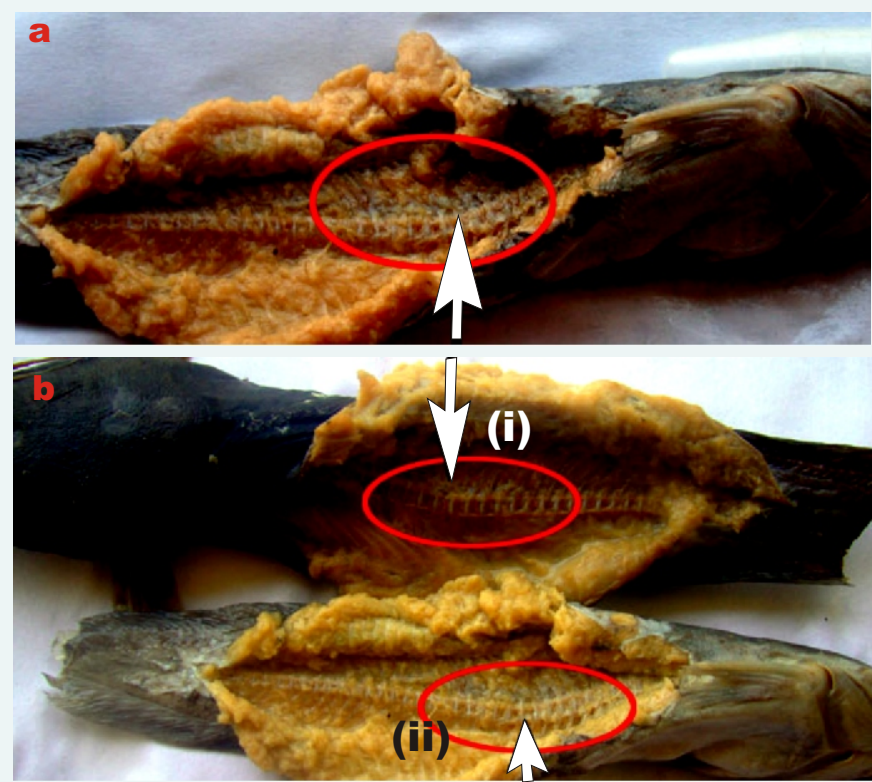

Figure 2: Vertebral column (Lordotic vertebrae) of C. batrachus kept under DD conditions during prespawning phase, started to bend gradually (a) After 30 days; (b) (i) After 45 days (ii) After 6 o days.

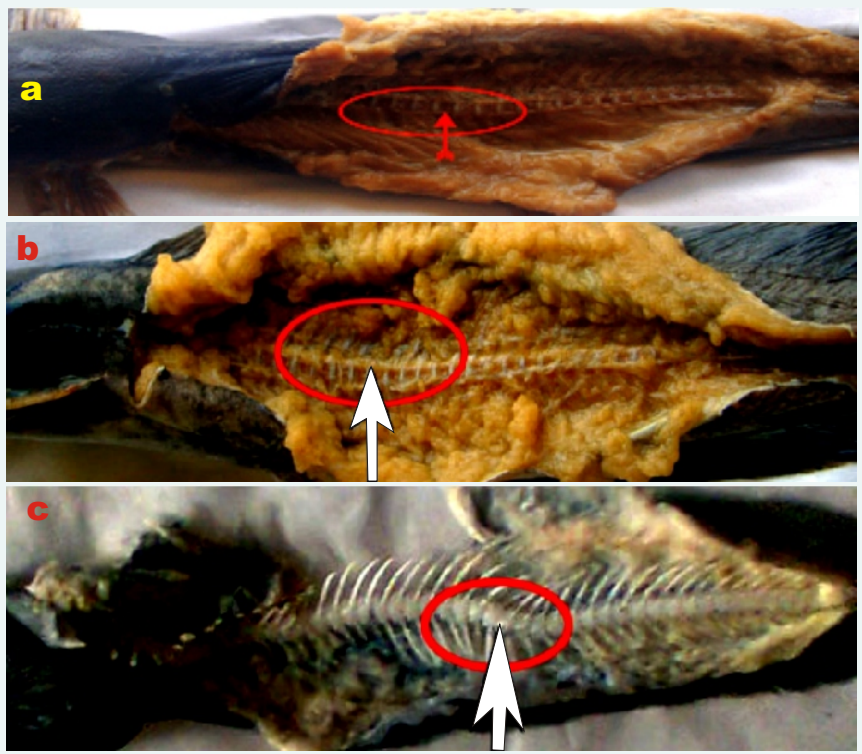

Figure 3: Vertebral column (Lordotic vertebrae) of C. batrachus kept under DD during spawning Phase, showing bend (a) After 30 days; (b) After 45 days; (c) After 60 days (ribs collapsed) 
structural changes in vertebral column were observed under constant light.

Earlier studies of Bolla \& Holmefjord (1988) \& Fjelldal et al. (2005) suggested light dependent spinal deformities in Hippoglossus hippoglossus and Salmo salar. They concluded that overgrowth of algal bloom, phytoplankton in the eutrophic pond may check the penetration of light and develop the complete dark condition in natural water bodies which might responsible for the vertebral column deformities in fish. However, several studies (Tutman et al., 2000; Härdig \& Höglund, 1984; Hamaza Chaffai et al., 1998; Sloff, 1982; Whittle et al., 1992 \& Massaudi et al., 2009) reported the occurrence of high frequency of spinal deformities in fish found in polluted water. Economic loss is a major outcome in fish industries due to deformities in shape (Jawad et al.,2017).

On the basis of present results, it could be concluded that constant dark may cause stress in the Clarias batrachus resulting lordosis.

Acknowledgements:

I am thankful to Prof. R.K. Agrawal, my PhD supervisor and Dr. Maya Shedpure for their supervision and kind help during my study. I am highly grateful to our Principal of our college for allowing me to avail the laboratory facilities.

\section{References:}

Afonso, J.M., Montero, D., Robaina, L., Astorga, N., Izquierdo, M.S. \& Gines, R., (200o): Association of a lordosis-scoliosiskyphosis deformity in gilthead sea bream (Sparus aurata) with family structure. Fish Physiol. Biochem., 22(2):159-163.

Akiyama, T., Arai, S., Murai, T. \& Nose, T. (1985): Tryptophan requirement of chum salmon fry. Nippon Suisan Gakkaishi, 51:1005-1008.

Al-Harbi, A.H. (2001): Skeletal Deformities in Cultured Common Carp Cyprinus carpio (L.) Asian Fish. Scie., 14(3):247-254.

Andrades, J.A., Becerra J. \& Ferrhdez-Llebrezb, P. (1996): Skeletal deformities in larval, juvenile and adult stages of cultured gilthead sea bream (Sparus aurata L.) Aquaculture, 141(1996):1-11.

Backiel, T., Kokurewicz, B. \& Ogorzalek, A. (1984): High incidence of skeletal anomalies in carp, Cyprinus Carpio, reared in cages in flowing water. Aquaculture, 43:369-380.

Bengtsson, Å., Bengtsson, B.E. \& Lithner, G. (1985): Vertebral defects in fourhorn sculpin, Myoxocephalus quadricornis L., exposed to heavy metal pollution in the Gulf of Bothnia. $J$. Fish Biol., 33(4):517-529.

Biswas, A.K., Seoka, M., Takii, K., Maita, M. \& Kumai, H. (2006): Stress response of red sea bream Pagrus major to acute handling and chronic photoperiod manipulation. Aquaculture, 252(2-4):566-572.

Bolla, S. \& Holmefjord, I. (1988): Effect of temperature and light on development of Atlantic halibut Hippoglossus hippoglossus larvae. Aquaculture, 74:355-358.

Carls, M.G. \& Rice, S.D. (1990): Abnormal development and growth reductions of pollock Therugra chulcogrumma embryos exposed to water-soluble fractions of oil. Fish. Bull.
$\underline{U S}, 88(1): 29-37$.

Couch, J.A., Winstead, J.T., Hansen, D.J. \& Goodman. L.R. (1979): Vertebral dysplasia in young fish exposed to the herbicide tri furling. J. Fish Dis., 2(1):35-42.

Dabrowski, K., Hinterleither, S., Sturmbauer, El-Fiky, N. \& Wieser, W. (1988). Do carp larvae require vitamin C? Aquaculture, 72(3-4):295-306

Eissa, A.E., Moustafa, M., El-Husseiny, I.N., Saeid, S., Saleh, O. \& Borhan, T., (2009): Identification of some skeletal deformities in freshwater teleosts raised in Egyptian aquaculture. Chemosphere, 77(3):419-425.

Favaloro, E. \& Mazzola, A. (200o): Meristic character analysis and skeletal anomalies during growth in reared sharp snout sea bream. Aquacul. Int., 8(5):417-430.

Fjelldal, P.G., Lock, E.-J., Grotmol, S., Totland, G.K., Nordgarden, U., Flik, G. \& Hansen, T., (2006): Impact of smolt production strategy on vertebral growth and mineralisation during smoltification and the early seawater phase in Atlantic salmon (Salmo salar, L.). Aquaculture, 261:715-728.

Fjelldal, P.G., Nordgarden, U., Berg, A., Grotmol, S., Totland, G.K., Wargelius, A. \& Hansen, T. (2005): Vertebrae of the trunk and tail display different growth rates in response to photoperiod in Atlantic salmon, Salmo salar L., post-smolts. Aquaculture, 250(1-2):516-524.

Frischknecht, R., Wahli, T. \& Meier, W. (1994): Comparison of pathological changes due to deficiency of vitamin $C$, vitamin $\mathrm{E}$ and combinations of vitamin $\mathrm{C}$ and $\mathrm{E}$ in rainbow trout, Oncorhynchus mykiss (Walbaum).J. Fish Dis., 17(1):31-45.

Gavaia, P.J., Dinis, M.T. \& Cancela, M.L. (2002): Osteological development and abnormalities of the vertebral colum and caudal skeleton in larval and juvenile stages of hatchery reared Senegal sole (Solea senegalensis). Aquaculture, 211:305-323.

Hamza-Chaffai, A., Roméo, M., Gnassia-Barelli, M, El Abed, A., (1998): Effect of copper and lindance on some biomarkers measured in the clam Ruditapes decussatus. Bull. Environ. Contam. Toxicol., 61(3):397-404.

Härdig, J. \& Höglund, L.B. (1984): Seasonal variation in blood components of reared Baltic salmon, Salmo salar L. J. Fish Biol., 24(5):565-579.

Hattori, T., Yoshida, M., Ohtani, H., Sugai, H., Ishigaki, T., Sasaki, M., Hayashi, T., Ozaki, S., Ishii, M. \& Kawai, A., (2003): A study of the distribution of star-forming regions in luminous infrared galaxies by means of $\mathrm{H}$ imaging observations. arXiv:astro-ph/oz11179v1.

Jawad, L., Akyol, O. \& Saglam, C. (2017): Consecutive repetition of lordosis- kyphosis in silverside Atherina boyeri Risso, 1810 collecteted from a wild pollution in Hom Lagoon, Izmir, Yurkry. Arch. Pol. Fish., 25:117-122.

Karen, D., Klaine, S.J. \& Ross, P.E. (2001): Further considerations of the skeletal system as a biomarker of episodic chlorpyrifos exposure. Aquat. Toxicol., 52(3-4):285-296.

Kranenbarg, S.,Waarsing, J. , Muller, M., Weinans, H. \& Van Leeuwen, J.L. (2005): Lordotic vertebrae in sea bass (Dicentrarchus labrax L.) are adapted to increased loads. L. Biomech., 38(6):1239-1246.

Klumpp, D.W., Humpherry, C., Huasheng, H. \& TAO, F. (2002): 


\section{RESEARCH ARTICLE}

Toxic contaminants and their biological effects in coastal waters of Xiamen China. II. Biomarkers and embryo malformations rates as indicators of pollution stress in fish. Mar. Pollut. Bull., 44(8):761-769.

Koumoundouros, G., Gagliardi, F., Divanach, P., Boglione, C., Cataudella S. \& Kentouri M. (1997): Normal and abnormal osteological development of caudal $\mathrm{cn}$ in Sparus aurata L. fry. Aquaculture, 149:215-226.

Kvellestad, A., Høie, S., Thorud, K., Tørud, B. \& Lyngøy, A. (200o): Platyspondyly and shortness of vertebral column in farmed Atlantic salmon Salmo salar in Norway description and interpretation of pathologic changes. Dis. Aquat. Organ., 39(2):97-108.

Lim, C. \& Lowell, R.T. (1978): Pathology of the vitamin C syndrome in channel catf ish(Ictalurus punctatus). L. Nutr., 108(7):11371146.

Lom, J., Pike, A.W. \& Dyková, I., (1991): Myxobolus sandrae Reuss, the agent of vertebral column deformities of perch Perca fluIviatilis in Northeast Scotland. Dis. Aqu. Organ., 12(1):49-53.

Mair, G.C. (1992). Caudal deformity syndrome (CDS): An autosomal recessive lethal mutation in the tilapia, Oreochromis niloticus (L.).J. Fish Dis., 15(1):71-75.

Marques, C.L., Rafael, M.S., Cancela, M.L. \& Laize, V. (2007): Establishment of primary cell cultures from fish calcified tissues.Cytotechnology, 55(1): 9-13.

Quigley, D.T.G. (1995): A lower jaw deformity in juvenile and adult Atlantic Salmon (Salmo salar L.). Bull. Eur. Ass. Fish Pathol., 15(6):206-209.

Rucker, R.R., Yasutake, W.T. \& Wedemeyer, G. (1970): An obscure disease of rainbow trout. Prog. Fish-Cult., 32(1):3-8.

Slooff, W. (1982): Skeletal anomalies in fish from polluted surface waters. Aquat. Toxicol. 2(3):157-173.
Ambient Science, 2018: Vol. 05(2); 40-43 DOI:10.21276/ambi.2018.05.2.ra06

Sfakianakis, D.G., Koumoundouros, G., Divanach, P. \& Kentouri, M. (2004): Osteological development of the vertebral column and of the fins in Pagellus erythrinus (L. 1758). Temperature effect on the developmental plasticity and morphoanatomical abnormalities. Aquaculture, 232(1-4):407-424.

Tutman, P., Glamuzina, B., Skaramuca, B., Kozul, V., Glavic, N. \& Lucic, D. (200o): Incidence of spinal deformities in natural populations of sandsmelt, Atherina boyeri (Risso, 1810) in the Neretva river estuary, middle. Adriatic. Fish. Res., 45, 61-64.

Vagsholm, I. \& Djupvik,O.,(1998: Risk factors for spinal deformities in Atlantic salmon, Salmon salar L. L. Fish Dis., 21(1):47-53.

Valenzuela, A.E., Silva , V.M. \& Klempau, A.E. (2007): Some changes in the haematological parameters of rainbow trout (Oncorhynchus mykiss) exposed to three artificial photoperiod regimes. Fish Physiol. Biochem., 33(1):35-48.

Wargelius, A., Fjelldal, P.G., Nordgarden, U. \& Hansen, T. (2008): Continuous light affects mineralization and delays osteoid incorporation in vertebral bone of Atlantic salmon (Salmo salar L.).J. Exp. Biol., 212(Pt 5):656-661.

Weis, J.S., \& P. Weis, H. (1989): Effects of environmental pollutants on early fish development. Revs. Aquat. Sci., 1:45-73.

Wiegand, M.D., Hataley, J.M., Kitchen, C.L. \& Buchanan, L.G.,(1989):..Induction of developmental abnormalities in larval goldf ish, Carassius auratus L., under cool incubation conditions. J. Fish Biol., 35(1):85-95.

Whittle, D.M., Sergeant, D.B., Huestis, S.Y. \& Hyatt, W.H., (1992). Foodchain accumulation of PCDD and PCDF isomers in the Great Lakes aquatic community. Chemosphere, 25(710):1559-1563. 